\title{
Effects of Drought and Climate Change on Forest damage and Its Hazard Assessment
}

\author{
Yongbin Bao ${ }^{1}$, Jiquan Zhang ${ }^{1, *}$, Xingpeng $\mathrm{Liu}^{1}, \mathrm{Li} \mathrm{Na}^{1}$, Yuhai Bao ${ }^{2,3}$, Qing $\mathrm{Ma}^{1}$ \\ ${ }^{1}$ School of Environment, Northeast Normal University; Institute of Natural Disaster Research, \\ Northeast Normal University, Changchun 130024, China \\ ${ }^{2}$ School of Geographical Science, Inner Mongolia Normal University, Hohhot 010022, China \\ ${ }^{3}$ Inner Mongolia Key Laboratory of Remote Sensing and Geographic Information System, Hohhot \\ 010022, China
}

\section{干旱和气候变化对森林病虫害的影响及其危险 性评价}

\author{
包勇斌 ${ }^{1}$, 张继权 ${ }^{1,}{ }^{*}$, 刘兴朋 ${ }^{1}$, 丽娜 ${ }^{1}$, 包玉海 ${ }^{2,3}$, 马晴 ${ }^{1}$ \\ ${ }^{1}$ 东北师范大学环境学院, 东北师范大学自然灾害研究所, 长春 130024, 中国 \\ ${ }^{2}$ 内蒙古师范大学地理科学学院, 呼和浩特 010022 , 中国 \\ ${ }^{3}$ 内蒙古自治区遥感与地理信息系统重点实验室, 呼和浩特 010022 , 中国
}

\begin{abstract}
Effects of drought and climate change on forest diseases and pests are increasingly significant, with the global change. As an important forestry zone in China, it is necessary to study on Daxing'an Mountains. Based on the forest diseases and pests and the meteorological data, we calculate SPEI and Humidity/Temperature $(\mathrm{H} / \mathrm{T})$ to analyze the impact of meteorological factors on diseases and pests and their dangers. Results: (1) Forest diseases and pests area increased at a rate of $0.76 \times 103 \mathrm{ha} / \mathrm{a}$. (2) There are 13 elements related to diseases and pests. Finally, May-Oct SPEI and precipitation, Sep sunshine duration, Aug H/T, annual average humidity and spring temperature were selected as the main influencing factors. (3) The danger level is centered on Huzhong, and decreasing to
\end{abstract}

*通讯作者：张继权（1965-), 教授, 博士生导师， 主要从事环境灾害风险评价与管理、预警等方向研 究。Email: zhangjq022@nenu.edu.cn the east and west sides. The Huzhong and Xinlin region are the key prevention and control regions.

Keywords: Forest diseases and pests; Drought; Climate change; Hazard

摘要

全球变化背景下, 干旱和气候变化对森林 病虫害的影响日益显著, 且大兴安岭作为中国 重要的林业之地, 有必要对其展开研究。基于 1998-2015 年森林病虫害资料及对应年份的气 象数据, 计算了 SPEI 和温湿系数, 以分析气 象要素对病虫害的影响及其危险性。结果表 明：（1）森林病虫害面积以 0.76 千公顷/a 的 速率呈增加趋势。(2)得出 13 个与病虫害相关 的气象要素, 最终选取生长季 SPEI 和降水量、 8 月温湿系数、 9 月日照时数、春季均温和年 均相对湿度作为主要影响因素。(3) 危险性等 级以呼中区的极高危险区为中心, 向东西两侧 递减。且呼中和新林区应为重点防治区域。 关键词: 森林病虫害; 干旱; 气候变化; 危险 性 


\section{1 引言}

森林病虫害是困扰我国林业发展的难题 之一 $[1]$ 。自 1980s 以来, 全球增温幅度更为 显著, 我国频繁发生暖冬、高温等异常气候和 干早等灾害, 直接或间接导致树木极易受有害 生物的侵袭 [2]。例如暖冬可造成病虫的越冬 存活率增加; 干旱使害虫的世代数增加, 且干 旱胁迫下树木抗病虫能力下降 [3], 均可能导 致病虫害发生范围的扩大。大兴安岭地区是我 国的重点国有林区和天然林主要分布区之一, 且该地区林业有害生物种类多, 发生频繁 [4]。 因此, 研究大兴安岭干旱和气候变化对森林病 虫害的影响及其危险性可为未来有害生物防 治及预警提供参考。

气象要素之间相互影响并共同作用于森 林病虫害, 但也各具其特殊的作用。气象要素 是自然因素中最主要的, 更是与病虫害发生密 切相关 [5]。近年来, 主要通过统计方法研究 森林病虫害与气象要素之间的关系, 并认为病 虫害主要与越冬期的气温、降水和春夏季的干 湿状况相关 $[6-7]$ 。但与干旱的研究较少。因 此, 本文以大兴安岭森林病虫害资料及对应年 份的月、季、生长季和年年尺度的气象数据为 基础, 通过统计方法篮选出主要影响因素, 同 时采用加权综合评价法对其进行危险性评价, 以期为未来森林经营和病虫防治提供依据。

\section{2 数据与方法}

\section{1 研究区概况}

研究区位于中国东北部, 包括黑龙江省的 大兴安岭地区、加格达奇以及内蒙古呼伦贝尔 市的松岭区 (图 1)。受蒙古西伯利亚高压影响, 冬季寒冷漫长, 春季多大风干旱, 最高温出现 在 7 月, 最低温度在 2 月。该区植被类型为寒 温带针叶林, 以兴安落叶松为单优势树种 [8], 是我国重要的林业基地。也是森林病虫害多发 区, 年均发生 64.845 千公顷。

\section{2 数据来源}

森林病虫害统计数据来源于中国林业统 计年鉴, 研究区内 6 个站点的气象数据来源于 中国气象数据网 (http://data. cma. cn/), 包 括月值气温、降水、湿度及日照时数以得到四 季、生长季 (5-9 月) 和年平均数据。记录长度
均为 1998-2015 年。森林覆盖率数据来源于 GLCF (http://www. landcover. org)。

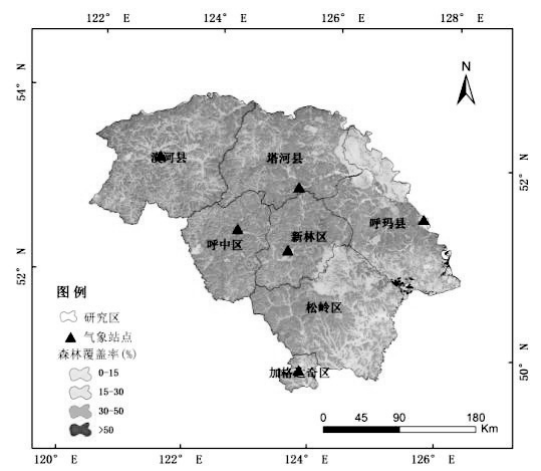

图 1 大兴安岭森林覆盖率

\section{3 研究方法}

\subsubsection{SPEI}

采用标准化降水指数 SPEI 表征干旱, SPEI 同时考虑了降水量及潜在蒸发量对干旱 的影响, 是一个具有多时间尺度特征的理想的 干旱指数 [9]。不同时间尺度的 SPEI 反映不同 时间长度的干旱程度, 比如 SPEI1 和 SPEI3 被 认为是与农业有关, 本文则选取 SPEI1 用于下 一步分析。参照国家气象干旱等级标准 (GB/T20481-2006), 将 SPEI $<0$ 定义为干旱, SPEI $>0$ 则为无旱。计算公式详见参考文献 [10]。

\subsection{2 气象要素确定与篮选}

选择气象要素要素包括月季年和生长季 尺度的 SPEI、气温、降水、相对湿度、日照 时数和温湿系数 (相对湿度/温度), 共 108 个 要素。首先通过计算病虫害面积与气象要素的 Pearson 相关性, 笁选出相关性较好的要素。 其次对其进行主成分分析, 选择载荷量大者为 自变量, 病虫害面积为因变量。最终利用线性 回归研究病虫害面积与气象要素和 SPEI 的关 系。线性回归的形式如下:

$\mathrm{Y}=\mathrm{aT}+\mathrm{bP}+\mathrm{cH}+\mathrm{dS}+\mathrm{eW}$

$\mathrm{Y}=\mathrm{fSPEI}$ 式中, $Y$ 为面积, abcdef 依次为气温、降水、 相对湿度、日照时数、温湿系数和 SPEI 的系 数。 


\subsection{3 危险性评价}

采用熵值法计算各评价指标的权重, 再通 过加权综合评价法得到危险性指数 [11]。计算 公式如下:

$$
H=\sum_{i=1}^{n} X_{i} W_{i}
$$

式中, $\mathrm{Xi}$ 表示各评价指标的量化值; Wi 为危 险性的权重; $H$ 则为危险性指数, 文中 $n=6$ 。

采用等距法划分危险性等级, 同时使用 IDW 插值法表示研究区内气象要素的空间分布 特征以及危险性区划。

\section{3 结果与分析}

\section{1 森林病虫害发生趋势}

由图 2 可知, 1998-2015 年间研究区内的 病虫害以 0.76 千公顷/a 的速率呈增加趋势, 其中虫害的增加速率为 0.97 千公顷 $/ \mathrm{a}$, 而病 害却以 -0.21 千公顷/ $\mathrm{a}$ 的速率呈减少趋势。以 距平大于 \pm 1.5-2 倍表示异常值 [12], 得出 1998 年为病虫害发生面积的异常偏小年份, 2000 和 2007 年为异常偏大年份。

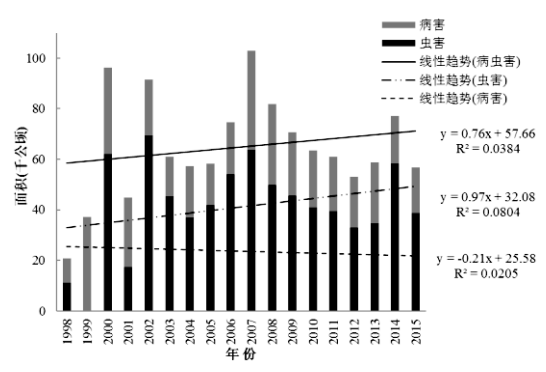

图 2 森林病虫害发生情况与趋势

\section{2 干旱和气候变化对森林病虫害的影响}

通过 Pearson 相关性分析, 选取了 13 个与病虫害有较强相关的要素 (表 1 )。其中 春季均温、冬季均温、生长季均温、9 月和生 长季日照时数为正相关要素, 而生长季 SPEI、 9 月 SPEI、夏季 SPEI、年均 SPEI、生长季降 水量及 8 月和生长季温湿系数与病虫害呈负 相关关系。生长季 SPEI、8 月温湿系数和生长 季温湿系数为显著负相关要素。表明生长季和 夏季的气象要素对森林病虫害的发生范围有 着较大影响。

表 1 气象要素与病虫害的相关性及主成分载荷矩阵

\begin{tabular}{|c|c|c|c|c|c|}
\hline \multirow[t]{2}{*}{ 气象要素 } & \multirow{2}{*}{$\begin{array}{c}\text { 相关系数 } \\
\text { 病虫害 }\end{array}$} & \multicolumn{4}{|c|}{ 主成分 } \\
\hline & & Y1 & $\mathrm{Y} 2$ & Y3 & Y4 \\
\hline 生长季均 SPEI & $-0.471 *$ & 0.958 & -0.018 & 0.008 & -0.103 \\
\hline 9 月均 SPEI & -0.296 & 0.714 & -0.437 & -0.182 & 0.296 \\
\hline 夏季均 SPEI & -0.333 & 0.862 & 0.251 & -0.074 & -0.306 \\
\hline 年均 SPEI & -0.456 & 0.850 & 0.165 & -0.156 & 0.298 \\
\hline 年均相对湿度 & -0.393 & 0.413 & 0.411 & 0.298 & 0.679 \\
\hline 春季均温 & 0.316 & -0.167 & -0.138 & 0.913 & -0.127 \\
\hline 冬季均温 & 0.367 & -0.329 & -0.620 & 0.253 & 0.388 \\
\hline 生长季均温 & 0.415 & -0.780 & 0.356 & -0.055 & 0.155 \\
\hline 8 月温湿系数 & $-0.480 *$ & 0.838 & 0.173 & 0 & 0.289 \\
\hline 生长季温湿系数 & $-0.608 * *$ & 0.832 & -0.089 & 0.259 & 0.023 \\
\hline 生长季降水量 & -0.416 & 0.922 & 0.217 & -0.013 & -0.171 \\
\hline 9 月日照时数 & 0.319 & -0.527 & 0.755 & 0.238 & 0.034 \\
\hline 生长季日照时数 & 0.346 & -0.809 & 0.023 & -0.383 & 0.297 \\
\hline \multicolumn{2}{|c|}{$\begin{array}{l}\text { 注: } * \mathrm{P}<0.05 ; * * \mathrm{P}<0.01 \\
\quad \text { 通过主成分分析法, 对以上 } 13 \text { 个要素进 } \\
\text { 行进一步地篮选, 结果如表 } 1 \text { 所示。四个主成 } \\
\text { 分 Y1、Y2、Y3、Y4 的特征根贡献率分别为 }\end{array}$} & \multicolumn{4}{|c|}{$\begin{array}{l}\text { 率 } 85.23 \% \text { ( }<<0.001) \text { Y1 主要体现 SPEI、温 } \\
\text { 湿系数和降水特征, Y2 主要体现日照时数特 } \\
\text { 征, Y3 主要体现春季均温特征, Y4 则体现了 } \\
\text { 年均相对湿度的特征。因此, 最终选取生长季 } \\
\text { SPEI、8 月温湿系数、生长季降水量、9 月日 } \\
\text { 照时数、春季均温及年均相对湿度作为病虫害 }\end{array}$} \\
\hline
\end{tabular}


的主要影响要素。

将 6 个气象要素作为自变量, 病虫害面积 (单位: 千公顷) 作为因变量, 进行回归分析并 得出以下方程:

$\mathrm{Y}=4.01 \mathrm{~T}-0.11 \mathrm{P}-26.8 \mathrm{H}+0.25 \mathrm{~S}-55 \mathrm{~W}+227$

$\mathrm{Y}=-20.7 \mathrm{SPEI}+63.2$

\section{3 气象要素的空间变化}

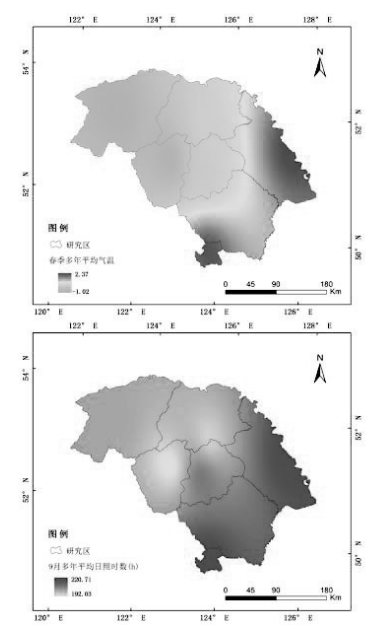

\section{4 森林病虫害危险性评价}

将以上选取的 6 个气象要素作为森林病 虫害孕灾环境的指标, 包括分子层、指标层, 并利用熵值法计算评价指标权重, 结果如表 2 所示。权重值表示该指标对病虫害形成的相对 重要性。采用加权综合评价法对大兴安岭森林 病虫害进行危险性评价, 同时采用等距法划分 危险性等级。

表 2 病虫害危险性评价指标及权重值

\begin{tabular}{ccc}
\hline 因子层 & 指标层 & 权重 \\
\hline & 春季气温 & 0.2011 \\
& 生长季降水 & 0.1558 \\
气象要素 & 年相对湿度 & 0.1437 \\
& 9 月日照时数 & 0.1653 \\
& 8 月温湿系数 & 0.2305 \\
& 生长季 SPEI & 0.1006 \\
\hline
\end{tabular}

如图 4 所示, 危险性等级以呼中区的极高 危险区为中心, 向东西两侧递减。极高危险区 和高危险区分别占全区的 $24 \%$ 和 $45 \%$, 主要分
图 3 提供了更为直观的信息, 即研究区春 季均温、生长季降水、8 月温湿系数、9 月日 照时数、年相对湿度及生长季 SPEI 的空间分 布图, 可为下一步的危险性评价作基础。如上 述可知, 病虫害发生与气温和日照时数呈正相 关关系, 相反, 与降水、SPEI、相对湿度及温 湿系数呈负相关关系。因此, 高温干旱地区的 危险性可能较高。
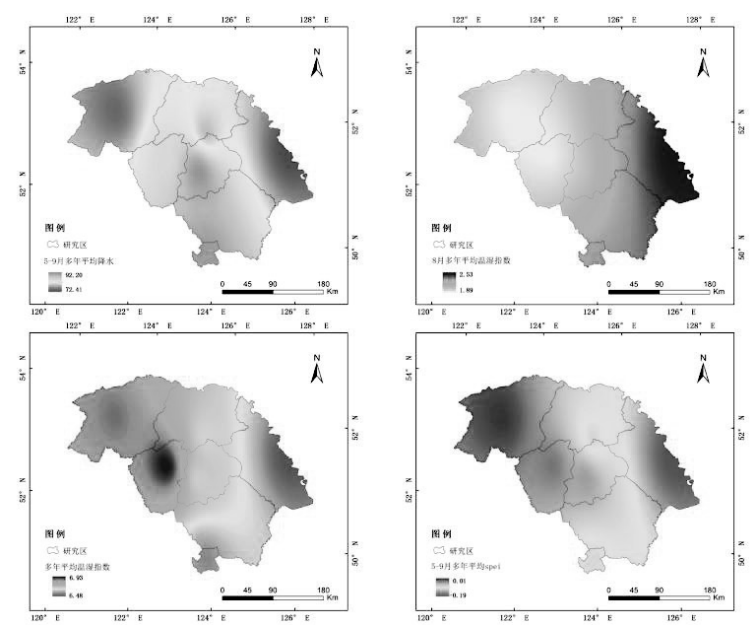

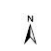

要素空间分布图

布在呼中、新林区和松岭区和加格达奇区。中、 低、极低危险区则分布在边缘地区, 分别占全 区的 $21 \% 、 5 \%$ 和 $5 \%$ 。气象要素是自然因素中最 主要的, 更是与病虫害发生密切相关。结合图 1 和图 3 可知, 漠河县气候偏湿润且温度较其 他地区低, 不宜病虫的生长发育及蔓延扩散; 而呼玛县东部森林覆盖率较低、其主要土地利 用类型为耕地、草地及建筑用地。因此, 在某 种程度上, 漠河县和呼玛县森林病虫害发生的 危险性指数较低。危险性指数越高, 表明病虫 害发生的可能性越大且损失较大, 以呼中和新 林区为中心的、松岭区北部以及塔河县西南部 应注意森林病虫防治及监测预警工作。

\section{4 结论}

本文采用相关性、主成分分析方法篮选出 6 个与病虫害发生相关的气象要素, 并通过熵 值法和加权综合评价法计算其危险性指数, 主 要得出以下结论:

（1）1998-2015 年间, 大兴安岭病虫害以 0.76 千公顷/ $\mathrm{a}$ 的速率呈增加趋势, 2000、2007 
年为异常偏大年份。病虫害以虫害为主导, 其 增加速率为 0.97 千公顷 $/ \mathrm{a}$, 病害却以 -0.21 千公顷/a 的速率呈减少趋势。

(2) 通过相关性及主成分分析, 最终选取 了生长季 SPEI、8 月温湿系数、生长季降水量、 9 月日照时数、春季均温及年均相对湿度作为 主要影响要素和危险性评价指标。

(3) 危险性评价表明, 中部地区危险性最 高, 且向东西方向递减。其中高危险区占比最 大, 为全区 $45 \%$, 主要分布在塔河县、松岭区 和加格达奇地区。

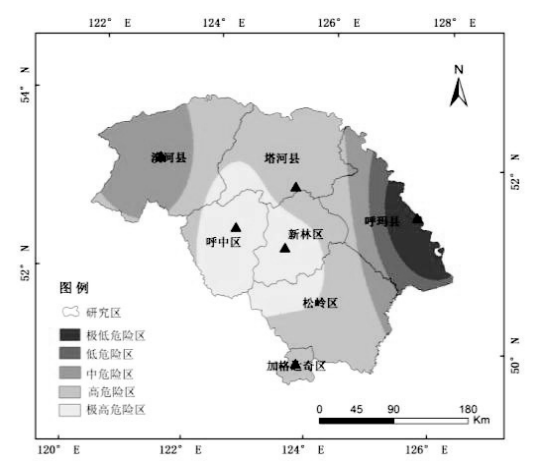

图 4 大兴安岭森林病虫害危险性区划图

\section{Acknowledgements}

This study is supported by "Twelfth Five-year" technology support program (2013BAK05B01)、 (2013BAK05B02) and National Natural Science Foundation of China(41561099、61631011).

\section{致谢}

本研究得到了 “十二五” 科技支撑计划项目 (2013BAK05B01)、(2013BAK05B02) 和国家 自然科学基金项目（41561099、61631011）的 资助。

\section{参考文献}

[1] 汪红, 舒清态, 吴秋菊,等.成像光谱遥感在 森林病虫害监测中的应用研究. 中国植保 导刊, 2018(1).

[2] 国家林业局.气候变化对林业生物灾害影
响及适应对策研究. 中国林业出版社, 60-70,2012.

[3] Wang X. The Analysis on the Effecting Factor of Drought Disease in Qingyang, Gansu. Journal of Risk Analysis and Crisis Response, 6(2):103, 2016.

[4] 于跃,房磊, 王凤霞, 等. 落叶松毛虫发生的 空间分布及其影响因子. 生态学杂 志,35(5): 1285-1293,2016.

[5] 王茹琳,王间利,姜洤,等.气象因子及气候 变化对森林病虫害发生发展的影响. 创 新驱动发展提高气象灾害防御能力.2013.

[6] Hart S J, Veblen T T, Schneider D, et al. Summer and winter drought drive the initiation and spread of spruce beetle outbreak. Ecology, 98(10), 2017.

[7] 王庆. 极端气候对三种森林虫害发生趋势 的影响. 中国林业科学研究院, 2016.

[8] 李顺, 吴志伟, 梁宇等. 大兴安岭林火发 生的时空聚集性特征. 生态学杂志, 36 (1):198-204,2017.

[9] Tong S, Lai Q, Zhang J, et al. Spatiote mporal drought variability on the Mong olian Plateau from 1980-2014 based on the SPEI-PM, intensity analysis and Hur st exponent. Science of the Total Enviro nment, 615, 2018.

[10] 马齐云. 草原干旱灾害损失快速评估研究. 东北师范大学,2017.

[11] He Y. Assessment Research of Bijie Drought Risk Based On Cloud Model. Journal of Risk Analysis and Crisis Response, 3(4):192-200, 2013.

[12] 张鹏霞, 叶清,欧阳芳,等.气候变暖、干旱 加重江西省森林病虫灾害.生态学报, 37(2): 639-649,2017. 